\title{
Examining relation between talent and competence through an experiment among 11th grade students
}

\author{
VERONIKA ÁRENDÁS
}

Abstract. The areas of competencies that are formable, that are to be formed and developed by teaching mathematics are well-usable in recognizing talent. We can examine the competencies of a student, we can examine the competencies required to solve a certain exercise, or what competencies an exercise improves.

I studied two exercises of a test taken by students of the IT specialty segment of class 11.d of Jedlik Ányos High School, a class that I teach. These exercises were parts of the thematic unit of Combinatorics and Graph Theory. I analysed what competencies a gifted student has, and what competencies I need to improve while teaching mathematics. I summarized my experience about the solutions of the students, the ways I can take care of the gifted students, and what to do to the less gifted ones.

Key words and phrases: talent, aptitudes, abilities, skills, creativity, problem solving, student assessment, manipulative materials use, technological tools.

ZDM Subject Classification: C44, D59, D69, K24, K34, U69, U79.

\section{Introduction}

Today it is a key issue in every country, what the school teaches to the students, and what for it disciplines. The standards of education highly contribute to the quality of human resources and the competitiveness of the country.

'The National Curriculum consistently identifies public education as the essential task of national culture, the transfer of the indigenous nationalities, the preservation of the universal culture, the elaboration of the susceptibility towards 
moral senses and emotional responsiveness. It should also be responsible for marshaling and developing a broad array of techniques, skills, knowledge, attitudes and information to meet the requirements needed for a job or a study. The public education is the foundation for the pursuit of the common good. It is to become a triggering factor of individual and universal development.' [14]

The contents, the requirements, and the goals of the education are also influenced by the expectations of the society and by some standpoints of psychology. While creating the plans of education and teaching, we must consider the psychological properties certain subjects have, and the psychological abilities they evolve or develop. The professional, precise and proper definition of a mathematical concept is not enough, the extensive application in practice is also a requirement.

'The National Curriculum intends to encourage the performance of students and teachers, as well, in order to evoke the acquired knowledge to be available for the current demand. Therefore, it equilibrates between the traditional values of culture and the new development objectives and contents.' [14]

As an active teacher I try to keep the goals drawn up by the NC (National Curriculum), and apply them in the teaching of mathematics, since this 'forms and enriches the whole personality and the thinking from the aspects of both emotion and motivation, and it provides knowledge that can be applied' [8]. Besides, I pursue to teach the students to solve problems efficiently. According to Klein, the main task of teaching mathematics is to educate the students for dialectic thinking and self-sufficiency in the areas of solving problems and self-testing [10].

\section{Theoretical background}

Because of its complexity, there is no unified definition for talent which is generally accepted and commonly used. Nothing proves better this complexity that the definition of talent is an interesting question for several various disciplines, e.g. psychology, engineering or arts.

From the aspects of both the developmental psychology and the school practice, Marland's definition is considered suitable, which considers other areas of outstanding performance than purely the intelligence. Moreover, his definition accepts both performance and skill as the criterion of identification. According to Marland, the gifted student is 'who give evidence of high achievement capability in areas such as intellectual, creative, artistic, or leadership capacity, or in specific 
academic fields, and who need services or activities not ordinarily provided by the school in order to fully develop those capabilities' [12].

The gifted students are, as claimed by Marland, who are identified by experts to have a certain outstanding ability and a real or potential capability in one or more areas to achieve extraordinary performances. Therefore, the student who only shows outstanding skill in a single area, and performs below average in others, could be also considered as gifted. [9] One can extend Marland's definition with another, according to which 'gifted individuals are those who demonstrate outstanding levels of aptitude (defined as an exceptional ability to reason and learn) or competence (documented performance or achievement in top $10 \%$ or rarer) in one or more domains. Domains include any structured area of activity with its own symbol system (e.g., mathematics, music, language) and/or set of sensorimotor skills (e.g., painting, dance, sports).' [13]

The concept of giftedness is very compound and manifold, thus many researchers interpret it in many different ways. Equally for researchers of psychology, representatives of school practice and workers of technical world it became necessary to have a definition that can be applied by everyone in their area of specialization. From the aspects of both developmental psychology and school practice, we can consider Marland's definition accepted, that is expanded even beyond intelligence, to the other fields of outstanding capabilities. Furthermore, it accepts both the capability and the performance as the criterion of identification. For this, he separated the following areas: general intellectual capability, specific learning (school) capability, creative thinking, leadership capabilities, artistic talents, psychomotoric capabilities. In his words, the gifted students are the ones for whom professionals ascertain some kind of outstanding talent and such real or potential capability, by which they can achieve exceptional accomplishments in one or more areas. Based on this, even that student, who only shows exceptional capabilities in one area, and in the other fields shows only capabilities below average can be considered gifted [9].

Measuring giftedness is also a complicated task, objective tests and subjective evaluations can help. The insights and evaluations of parents, educators, teachers and development specialists are of significant importance in recognizing and developing talent [2]. This paper is to give guidance in talent recognition, but generalization based on solely this work should be avoided. However, there are studies with the declared goal of inventing a recognition process [11].

The gifted student thinks differently than his/her less gifted companions. $\mathrm{He} / \mathrm{she}$ creates different action plans, looks for or discovers different correlations, 
or evaluates things differently. In addition, the cognitive capabilities, the creative personality virtues, the development of thinking operations, the good personality characteristics, and also the suitable external conditions are indispensable ([8]). For the capability of solving a problem, besides understanding the problem itself, inter alia creativity, recognizing correlation, judgmental capability, the capability to prove, transferring, and capability for combinatorial thinking are necessary. The conversion between Bruner's representational levels (material plane, iconic plane, symbolic plane) improves the flexibility and the efficiency of delivering solutions ([1]). The efficient problem solving is a difficult thinking procedure, and is necessary for the completion of mathematical and other social activities. Besides that, it is one of the capabilities by which talent can be recognized. If a student bears significantly more capabilities, that are significantly more developed then the others, and if he/she continuously uses these while solving problems, shows his/her talent.

The supporting environment plays an emphatic role in avoiding losing the talent of a student. We hope that they discover the talent that the student has, and hope that he/she will make good use of it, because for this, he/she is going to have to put a lot of work, time, energy and effort in it, just as his/her teacher has to. For teachers, the development of a talent requires great extra effort, pedagogical discretion, psychological qualifications, methodological refinement, preparedness, empathy and understanding, together with the good teacher-student relationship. Since, as Rókusfalvy has written: 'In this capability the base is the talent, but that only means the possibility to start out, one needs to be smart about that, use and develop that' [20].

For developing talent in practice, three methods are indispensable (according to Balogh): enrichment, the acceleration and the individual differentiation [3].

'Differentiation receives much attention in the world of education, and essentially it means the endeavor for recognizing the individual differences and the pursuit and application for such organizational strategies, that respect the individual differences in a development process, and at the same time, respect the development principle of the integration.' [3]

There are cases depending on age, development and talent, where the student does not have to go through every single one of Skemp's knowledge acquirement phases step by step (like activity, gathering experience, gathering of essential conceptions, filter noises, the formation of simple notions and the related knowledge, the formation of high level notions and the related knowledge, building relations between the different notion systems $([7]))$. This can be one way of acceleration. 
Although 'everybody needs to build his/her own notion system, but we can make this process faster if we have all the material that we need in our hands' [21]. The materials that we need mean inter alia competence, motivation, the right forms of working, methods, tools, textbooks, and teacher activity. We can usually say that the student, who does not join the process at the first step, just later, is gifted.

Skemp's psychological approach ([5]) is strongly related to Pólya's teachinglearning principles (1. Principle of active learning, 2. Principle of motivation, 3. Principle of consecutive phases $([18])$ ), since both theories suggest active learning, discovery and gradualism. The student with good mathematical capabilities can discover new contexts, methods of solution or can even try to use his/her knowledge in other areas after the procession of his/her experiences. By this the teacher could get the most out of his/her student.

The areas of competencies that are formable, that are to be formed and developed by teaching mathematics are ordered in competence lists. The analysis of this paper is based on the competence list of Czeglédy ([7]). Czeglédy defines the following areas of competencies: 1. Reading comprehension 2. Problem solving skill, 3. Counting skill, 4. Experience in cognitive operations, 5. Creative attributes of personality, 6. Skill of algorithmic thinking, 7. Skill to plan solutions, 8. Combinatorical thinking, 9. Skill of application, 10. Function-like thinking, 11. Orientation in time and space, 12. Urge of proving, sense of judgement, 13. Recognition and application of geometric transformations in practical examples, 14. Application of probability theory in everyday life. Besides the list of competencies I use here, other lists exist as well, with differences in the definitions and structure. For example, the NC ([14]) defines mathematical competence in a more general sense, and by focusing to the everyday applications of mathematics. The PISA (Programme for International Student Assessment [15, 16, 17]) introduced several changes in 2015, modifying the data collection, the content and task kit of natural science, the statistical methodology, the structure of the tests, the organization of the measurements, and most importantly for us, the six skill levels.

\section{Question of research}

My examination does not map the depth of the students' knowledge in a specific subject. Instead, it tries to find the answer for that by gaining mathematical knowledge, what kinds of proficiencies, capabilities, facilities are formed 
or improved in the students, for that what kinds of competencies do the gifted students have, and for that what kinds of competencies should be developed while teaching mathematics in the group I have examined and I teach. My goal is to use the two exercises to find the students in the group who could be nominated as gifted. Besides, this study could also act as a reflexion of my work as a teacher.

\section{The circumstances of the research}

I teach the IT specialty segment of class 11.d of Jedlik Ányos High School in Budapest. In the group that consists of 16 people, only 1 girl studies. The group is especially inquisitive about mathematical problems, and susceptible for supplementary material, as well. 9 of the students in the group takes official extra classes in Mathematics, and 4 of them would like to take the advanced level highschool graduation exam. During the classes I often use differentiation, because the requirements of the mid-level and the advanced level graduation exam are very different, for example, the students do not need to know any proofs in the mid-level, while at the advanced level, it is included in the oral exam as well. Furthermore, there are differences in the knowledge of those who will take the mid-term exam.

The exercise and problem I analyzed were part of the test at the end of the thematic unit of Combinatorics and Graph Theory. The difficulty of the problems were different. The first four exercises and problems were about graphs, and the following 6 were combinatorial problems. I based my analysis of the problems by the areas of competence on the capability measurement shown in [6].

The two examples chosen:

(1) Sketch the graph that has 8 vertices, 12 edges, and every vertex has degree of 3 !

(2) How many 5 -digit, numbers divisible by 6 can be made using the numerals: $1,1,5,8,9$.

My endeavor was to choose one relatively easy and one rather more difficult example from the test, and to choose one from each thematical area. The first example was a problem, while the second one was an exercise, thus they differ by their solution. For the exercise, students are supposed to know a direct approach to the solution, however, they are not supposed to know one for the first case ([4]). My view is that finding solutions for these two problems rely on the combined existence of more than one competence. 


\section{Experiences}

In solution of the first problem, one had to follow a certain order of steps: sketch the 8 vertices of the graph, draw the 12 edges while continuously examining how the degrees of the vertices change, and finally, verify how many edges there are. It was expedient to follow these steps while constructing the solution, and not only use blind guessing. This problem has many essentially different solutions, and the students found many of those, these can be seen in Figure 1.
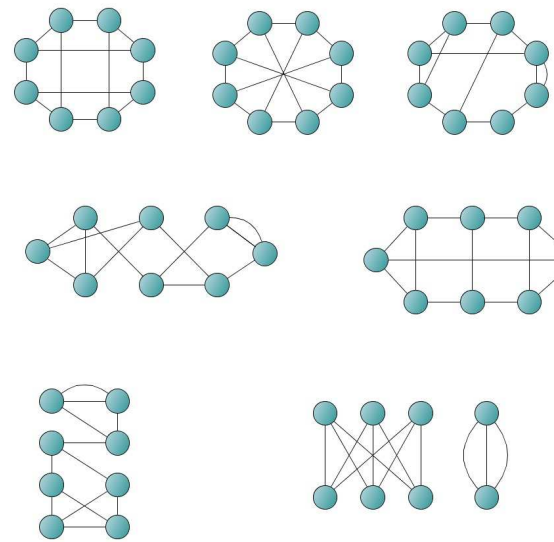
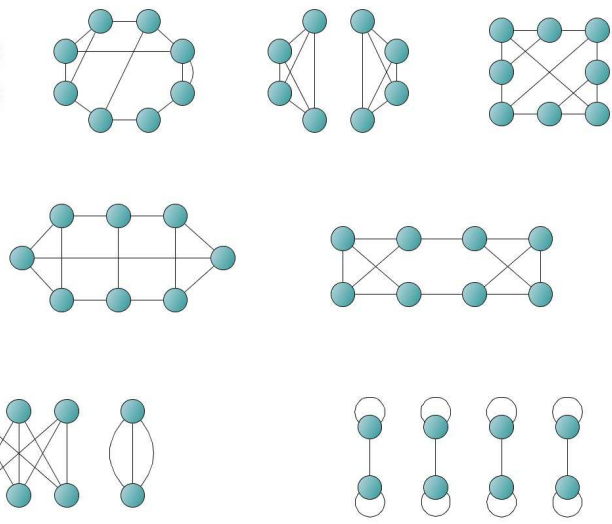

Figure 1. The solutions given by the students for the first problem

It is not always easy to plan and execute the steps of the solution. The formation and the development of certain series of action is not formed spontaneously in the student, but part of a long procedure. In Number Theory, in the algorithm of the prime factorization, the edges of the graphs are associated with the particular steps of the factorization. Thus, the area of graphs can be suitable for being present in algorithmic thinking, even on the level of practice.

There were only a few conditions in the first problem. For the student, this can be just as confusing as if there were many. The amount of confusion it caused for a student shows information about the state of their combinatorial thinking. This area of competence includes the processing of all the information, the examination of all the conditions, the consideration of the correlations, and the finding of every solutions.

A lot of right solutions could be found to this problem. At some sorts of problems, the conscious experimenting can easily be seen, for example, when a 
student sketches many bad solutions that are seemingly not similar, or there is not a pattern recognizable that shows how the steps follow each-other. In this case, the student's capability of solving a problem is not very high. It is not out of question, though, that he/she finds a right solution. There were only two students in the group, who did not find a right solution in the first try. This does not mean that they do not possess the capability of solving a problem, or that all the others do possess that. It was possible to find a solution in the first blind guess, since this problem had a lot of solutions. Actually, only the discussion of the test could reveal the exact thoughts of the students, and show the ones who used a certain plan to draw the figure, instead of guessing.

Typically at this problem, we can discover the consciousness and the planning behind a certain solution, after verbally talking over that. When the students exposed their solutions, everyone told that he/she looked at the given data in the problem, then sketched as many vertices as there were mentioned in the text. After these, there were students who started guessing, perhaps wrote the degrees on the corresponding vertices, but there were students who thought everything through before sketching. Of course, a single problem and the discussion is not enough for us to be able to tell a student's capability of laying out the solution, but anyway, we may get a preliminary picture of that.

When handing out the tests, we talked over every one's solution to this problem. Everyone draw his/her solution on the board individually, one by one, and the class took a look at it if it is a right solution indeed or not, and if it is essentially different from the previous solutions or not, since there were isomorphic graphs, that we had to check. The students were inquisitive about the solutions of the others, and were astonished again seeing how many different solutions problem can have. Using the discussion method, the students committed themselves to certain graphs, and they brought up pros or cons for the sketches. Bruner's levels of representation could be observed at the sketching, the exposal and at the reasoning, as well. [1]

Every student had understood the question, since every one of them handed in a reasonable solution. Also that is clear, that there were only two students who did not sketch a suitable graph for the first try, but they began to sketch a wrong solution. All the others could draw a graph that fulfills the conditions for the first try. The two students, who did not find a right solution for the first time, came up with new ideas that finally proved to be good. That is, they did not give up and tried a different method, a different idea. The problems that the class had previously solved in classes could mean help for the students. 
One of the creative personal characteristics, inventiveness, can be especially well improved by problems with graphs, similar to this one. Besides inventiveness, the creative personal characteristics include issue sensitivity, flexibility, elasticity, ease, genuineness, elaboration, reformulation, expansion, and transferring, as well.

If after an unsuccessful try, the student can discover a new idea soon, and does not get stuck with the idea that does not work, then that student may have the characteristics of ease. Flexibility, elasticity and ease are strongly related. The combination of these is peculiar for a student if he/she is able to take notice and present of more than one solutions. As far as these solutions are different by nature, the flexibility is a characteristics of the student, if they are not essentially different, then the student has the elasticity characteristics. It is important to note though, that these categories make each other stronger, and elasticity is a precondition to flexibility. Flexibility was mostly observable during the discussion of the solutions. Namely, this shows the ability to change the approach. It makes it obvious how the individual can ring the changes on his/her ideas, while changing the approach repeatedly, and it helps getting to the next element/solution from the previous one. Some students could do this very well, but there were some, for whom it was hard to let his/her solution go. The teacher plays an emphatic role in the development of these, thus one needs to try to make the students think and examine problems in multiple ways. This is why every solution was written to the board while talking over the test.

It is easy to see on Figure 1, that the graph in the bottom right corner is very different from the other solutions that were handed in. That student's work was inspired by a whole new, unique idea. The one in the bottom left corner, and the fourth graph in the first row are interesting, as well. These students sketched really unique, new graphs that are completely different from what the others drew. The student with the capability of genuineness sees and evaluates problems very differently from the others, their solutions often differ from the usual. 14 students handed 11 different solutions for this problem.

During the discussion of the problems, by asking the proper questions, the reformulation capability of the students could be improved - which is the capability to bring the new problem closer to the familiar ones - , and also the expansion, using which the student could analyze whether a certain expression is valid in another context. These show high level of creativity. The discussion, and the brainstorming about the problems went so far after the discussion of the original problem, that some students could sketch the graphs of the tetrahedron, the cube and the octahedron, and could come conclusions from these - and the 
other could even ask further questions. These graphs are shown on Figure 2. The graph in the middle would have been a possible solution for the problem in the test, but none of the students drew this.
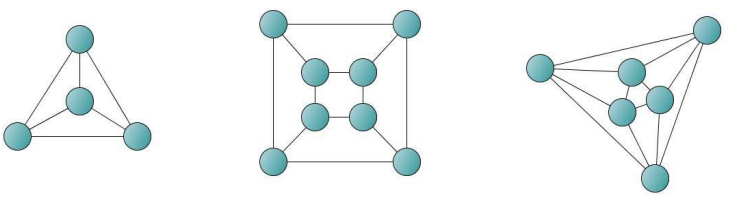

Figure 2. Tetrahedron, hexahedron, octahedron

The problem was intentionally very similar to a previous one, when they had to draw a graph that had exactly 4 vertices, 6 edges, and all the vertices had a degree of 3. This graph is the first one on Figure 2, and the second graph is a possible solution to the actual test problem. It could mean much help if a student recognized the type of the problem, or remembered the previous one. It is likely that the student who recognized this has the competence of function-like thinking, since he/she found the connection between the two problems, and he/she had to align his/her knowledge to the data given in this problem.

In the area of graphs, there are many great exercises for spatial orientation. All sorts of public transports or road systems, for example, the subway systems or the railway lines may be a reasonable choice for raising, understanding and solving a problem. Until we talked over the problem together, none of the students discovered the solution shown in the middle of Figure 2. After some leading questions, though, one of them noticed it, and then at once the others remembered the solution of the previous one, that is shown in the first graph of Figure 2. When the student drew that on the board, he instantly had the 'AHAM' experience, because he shouted 'But this is a tetrahedron!' at once. The topic of graphs in general is especially good for the demonstration and the examination of planar and spatial shapes.

As the apropos of the problem, the planar drawing can be associated to a spatial shape. By the help of the old Babilon game set, the student can examine the solutions with manipulative tools as well. It is by all means worth to put emphasis on the manipulative representational plane on the classes of introduction to the area. In the plane, even with buttons and straws can be used for modelling the graphs, if the student is paying attention to always place a button to every end of every straw. 
The topic of graphs is especially suitable for transferring. Namely, transferring is the application of knowledge to subjects, or topics, that seemingly differ from the certain knowledge. In this area, the students could see many examples of this, I myself also try to always show connections in between and outside of mathematics, so that the students can see a more overall, and more complex picture of the whole.

The topic of graphs can tangentially help in the development of the competence of the recognition and the application of geometrical transformations in practice, since there are good exercises to colorings, tile patterns, maps, and layout designs, as well. By this, graphs can even show up at geometry, even geometry can show up at graphs to demonstrate the application of mathematical knowledge.

We need to form such a mathematical knowledge for the student that can be applied. Not the mathematical content is the main reason to have that knowledge, but the ability to apply these. It is very motivating if the student can see the profit he/she gains from studying, and the social expectations are also tending to that this is the area where a student needs to perform well. It is worth showing examples at the very beginning of the thematic unit that show the practical side of the new learning. The topic of graphs is very good for demonstrating the application in practice. Some example to the application of graphs: mathematics (prime factorization, geometrical network of edges); biology (leaf veins, the growth of a tree, populations, the reproduction of rabbits); chemistry (the structure of hydrocarbons); geography (road networks, maps); information technology (the mutually unequivocal association between directed graphs and monitor cells, the structure of popular social media sites); history (the bridges of Königsberg); physical education (the organizing of a championship).

The second example was about permutation with repetition, expanded with a bit of number theory that also makes the internal connections of the subject and the transferring stronger.

When solving the exercise, one had to examine when a number is divisible by 6 . (A number is divisible by 6 if and only if it is divisible by both 2 and 3.) Because of this, the five-digit number had to have an 8 at its last digit. The other digits could be ordered in 4 ! different ways. But two of the possible digits are ones, and changing these two in a number will not change the number itself, thus we have to divide the result by 2. After all these, one had to give a worded answer. So, the solution is $\frac{4 !}{2 !}=12$. Answer: 12 6-divisible, 5-digit numbers can be formed out of the numbers $1,1,5,8,9$. 
The student, who listed all the possible numbers as a second solution has the characteristics of flexibility, since the two ways of solving the same exercise are completely different. The second solution is also suitable for verification, by the way.

Elaboration makes it possible for a student to work his/her own idea out, and to plan the method of solving the exercise. To do this exercise, one has to follow these steps, one by one: examine when a number is divisible by 6 , what number is suitable for the last digit of the numbers we were looking for, and that how the rest of the numbers could be put into order. Most of the students also drew small placeholders for the digits, as a part of the planning the number of digits the solution has, and they put the ones they already knew about into it (like 8 to the last digit). Purposefulness, elaboration can easily be seen at this exercise. Out of the four students who gave perfect answers two did not sketch placeholders. They did not need those, they could see through the exercise even without that. They joined Skemp's knowledge acquirement phases at a later point.

In the solution, they had to justify their certain steps, for example that why 8 has to be the last digit. They had to take the logical consequences consistently, one by one. It can be seen on the tests that which student examined the causeeffect correlations, and solved the exercise with consistent thinking. Only a few can write down a trimmed train of thought, but the ones who do that, have the competence of proof directive, judgement.

Therefore, it is worth creating some kind of systematic working, when solving combinatorial exercises. Often it is too complicated to line up every single solution or the conscious - or maybe the blind - guessing, but instead the algorithmic thinking method can be formed in the student, that makes him/her able to solve further exercises or problems of this kind.

Planning could be recognized very often amongst the solutions that were handed in. For example there were students who justified, added text notes or drew placeholders for the numbers for the steps at the side of the lines. There were no students who did find the good solution to the exercise, but could not justify it, or made a wrong justification. This shows that the students, who gave a good solution, or at least started to think the right way, did not just randomly make operations with the data of the exercise. Therefore the student, who can filter the necessary parts of the information, the data and the effects to solve the exercise, and after finding the connections can determine the optimal route of the solution, has the competence of planning the solution, purposefulness, expediency. 
Both the capability to plan the solution and the algorithmic thinking presumes the optimal series of actions, however, while the planning is a conscious action, that happens before the activity itself, the algorithm can also be formed accidently.

While giving the solution, one had to think over the certain conditions. If the student checks if he/she examined all the data, conditions, connections, if he/she did not calculate certain cases more times wrongly and if he/she gave all the different, good solutions, then he/she completely has the competence of combinatorial thinking. Many students did not notice that changing the two ones results in the exact same solution, thus they did not filter out half of the cases, which they have already counted before. This might be a divisional borderline among the students.

It shows the development level of the counting skill, capability of rounding, estimation, that how conscious mathematical activities his/her calculations are. It is strongly related to working with less mistakes and with more knowledge of the correlations, and to know applications in the practice. Knowing and using the meaning of factorial could have been useful for solving the exercise. Besides that, one had to divide by 2 , or 2 factorial, then simplify the expression. Anyway, the good approach is to have conscious activities in the background of the solution, instead of conning, that makes no sense. Unfortunately it happened that a student tried to apply a correspondence that did not fit the exercise - but he was aware of the fact that his solution is not good already at the moment he handed the test in.

Only some of the students realized that they have to deal with the placement of the two ones. They understood the exercise indeed, and could give the right solution. There were no signs of any other student being aware that they have to pay attention to the cases that they counted more times because of the ones. It can definitely be seen that the sensibility for the problems, and the capability to solve a problem is developed in the four students who could deliver a good solution to this problem, since they saw, understood, and solved the problem of the certain exercise.

In the thematic unit of probability theory, there are many combinatorial exercises with little extensions, like determining the number of the preferential cases and the number of all the cases, then the probability. This is something that also makes it important for the students to know methods for solving combinatorial exercises, and to have these kinds of examples even while examining other topics. The exercise we examined can be used in number theory, combinatorics or also 
in probability theory, developing thus the competencies of applying probability theory in everyday life and the capability of application in practice.

\section{Conclusion}

The results were slightly worse than expected. The test contained 10 examples for 46 points. The first four examples, which were about graphs, were definitely well-received by students. They will also meet combinatorics in the thematical unit 'Probability theory and statistics', where the deficiencies could be smoothened, and more exercises could be solved. Table 1 shows the points earned by the students, and the corresponding grades. Only one test received an excellent grade, which, by the way, contained only perfect answers. Two students were missing on the day of the test, thus they are excluded from this analysis.

The varied difficulty of the examples is proved by the differences in the earned points. For the analyzed graph theory example, everyone submitted a correct answer, thus everyone received 3 points. In the case of the other example, the variance was fairly high. This (latter) example was worth 5 points. One could earn 2 points for the inspection of the divisiblity by 6 ; one point for including 4 ! in the solution; one point for the division because of the two 1s; and the last point for the correct result and the answer. One student tried to use an incorrect form, because of the misunderstanding of the exercise, thus receiving 0 points. 3 students earned 2 points, one student earned 4 points, and 4 students earned 5 points. Interestingly, every student was able to solve the problem, and the exercise was the harder one of the two. In my opinion the most likely cause is that many students tend to think in formulas. This leads to solution ideas with formulas that first came to the mind, and these are usually incorrect. The post-verification is also missing in the thinking process, as students do not check whether their selected formula really expresses their idea.

Out of the 14 competencies that can be developed by teaching mathematics ([7]), 12 occurs in the two examined examples. Therefore a student, who solved the test without a mistake, could be nominated as gifted, for having the most of the competencies, and applying these in the problem solving. Obviously two test examples, or even a whole test are not enough to decide upon the students' giftedness without error, however, if a student's competences seem to be outstanding in other cases, it becomes a necessity to deal with him/her in a special way. We can proceed faster with him/her than with the whole group. That is, we can use 


$\begin{array}{cc}\text { Score } & \text { Grade } \\ 24 & 3 \\ 33 & 4 \\ 37 & 4 / 5 \\ 37 & 4 / 5 \\ 46 & 5 \\ 30 & 4 \\ 34 & 4 \\ 37 & 4 / 5 \\ 26 & 3 \\ 33 & 4 \\ 25 & 3 \\ 30 & 4 \\ 29 & 3 / 4 \\ 37 & 4 / 5\end{array}$

\section{Intervals of grades}

$\begin{array}{cc}38-46 & 5 \\ 37 & 4 / 5 \\ 30-36 & 4 \\ 29 & 3 / 4 \\ 23-28 & 3 \\ 22 & 2 / 3 \\ 16-21 & 2 \\ 15 & 1 / 2 \\ 0-14 & 1\end{array}$

Table 1. Points and grades earned by students

acceleration at his/her case, as a talent development method, the point of which is to guarantee the frame for him/her to proceed faster.

Since I often give this student extra problems that are somehow related to the topic of the actual class, but are somewhat more complicated, I can make great use of the methods of enrichment and benefication, which ones' goal is to 'extended improvement of the knowledge and the capabilities depending on operations' [3]. He takes these exercises with interest, and he is always curious whether he could give the right solutions for them. 
I can even discuss problems in the breaks between classes with this student, but unfortunately he can not take the facultative classes because of the other activities he does. Therefore I find it even more important to give him extra attention, extra problems and additional information in mathematics classes. Unfortunately, he is not really communicative with his classmates, thus working individually and the personal treatment are the sufficient solutions.

There are some students in the group, who are really inquisitive about mathematical problems, and the application in practice. Relative to their age, they also are at an advanced level in many areas of competence, thus they can be also nominated as gifted students in mathematics. I have been using the enrichment and beneficiation method for them for years, as well. In the last year, they stayed in every break after the classes to solve and discuss additional exercises. In the beginning, I prepared the problems, showed them help on the internet, then they looked for interesting stuff on the internet, and finally, a regular workshop was formed, so that we have time to talk about these. They brought questions even later, but I also took for example some exercises from the mathematics criteria class of the Faculty of Science of Eötvös Loránd University. Besides, they created a smartphone application to solve a quadratic equation, and a computer program to plot cubic functions, and to change between number systems. All this by their own diligence, for themselves. Right now, because of the facultative and the new classes, the students postponed the workshop, and they came back to bringing problems during the breaks between classes, but in the second semester there will be demand for it again, so the workshop will be continued. With these students, differentiating is very effective. I believe that it is important to introduce the students to problems that essentially differ from the ones they meet in the books. Since the group is good with mathematics, some of them would like to pass the advanced level graduation exam and many of them take the facultative class, as well, I often take more complicated problems to class. I consider it important to give examples for the students which are significantly different from the textbook problems, even if these problems are difficult, as the group is good in mathematics, and more students plan their further education in the STEM fields. The students actually plan, work, research, draw and code helping each other after some well-directed questions. It is challenging for me to be able to propose interesting, good, useful mathematical problems for them both in the classes and in the workshops.

I try to develop many competencies of the less gifted students of the group as for the more gifted ones, as well. This is why I often use differentiating in their 
case, as well. They often get exercises that are somewhat easier, that we talk over together, and we always start Skemp's knowledge acquirement phases for the first step. In their case, to keep up the interest, and to achieve the necessary motivation, I try to create the descriptions of the exercises so that it fits their areas of interests.

Being an IT faculty class, I put great stress on the application in practice. If possible, I push them to use ICT tools, and I try to use the three practical methods of developing talent both in classes and in the workshops.

\section{References}

[1] A. Ambrus, Bevezetés a matematikadidaktikába [Introduction to mathematics education], ELTE Eötvös Kiadó, Budapest, 2004 (in Hungarian).

[2] E. Bagdy, Z. Kövi, Z. Mirnics, Fény és árnyék - A tehetségerõk felszabadítása [Light and shadow - Freeing the powers of giftedness], Magyar Tehetségsegítõ Szervezetek Szövetsége, Budapest, 2014 (in Hungarian).

[3] L. Balogh, G. Kovács, A matematikai tehetség fejlesztése [Developing mathematical giftedness], Magyar Tehetségsegítõ Szervezetek Szövetsége, Budapest, 2010 (in Hungarian).

[4] Paul J. Campbell, Louis S. Grinstein, Mathematics Education in Secondary Schools and Two-Year Colleges, Garland Publishing, New York, 1988.

[5] I. Czeglédy, G. Orosz, T. Szalontai, A. Szilák, Matematika tantárgypedagógia 1., fõiskolai jegyzet [Mathematics subject pedagogy I., high school lecture notes], Calibra Kiadó, Budapest, 1994 (in Hungarian).

[6] I. Czeglédy, Teljes körũ matematikai tantárgyi képességmérés Miskolc város általános iskoláinak 6. osztályában [Comprehensive ability measurement in the subject of mathematics in the 6th grade classes of Miskolc], Miskolci Pedagógus folyóirat 45 (2008) (in Hungarian).

[7] I. Czeglédy, Kompetenciaalapú matematikaoktatás [Competence-based mathematics education], TÁMOP 4.1.2-08/1/a-2009-0038, Eger, 2010 (in Hungarian).

[8] I. Czeglédy, A matematika tanításának pedagógiai-pszichológiai vonatkozásai [Pedagogical and psychological aspects of the teaching of mathematics], TÁMOP 4.1.2-08/1/a-2009-0038, Eger, 2010 (in Hungarian).

[9] I. Czeglédy, T. V. É. Rozgonyi, Tehetséggondozás az iskolai oktatásban, fõiskolai jegyzet [Talent management in the education, high school lecture notes], Nyíregyházi Fõiskola Tanárképzõ Intézet, Nyíregyháza, 2009 (in Hungarian).

[10] S. Klein, A komplex matematikatanitási módszer pszichológiai hatásvizsgálata [Psychological impact assessment of the complex mathematics education method], Akadémiai Kiadó, Budapest, 1980. 
[11] K. Kontoyianni, M. Kattou, D. Pitta-Pantazi, C. Christou, Unraveling Mathematical Giftedness, CERME 7 - Proceedings of the Seventh Congress of the European Society for Research in Mathematics Education (2011), 1066-1074.

[12] Marland, S. P., Education of the gifted and talented: Report to the Congress of the United States by the U.S. Commissioner of Education and background papers submitted to the U.S. Office of Education, 2 vols., Washington, DC: U.S. Government Printing Office, Washington D.C., 1972.

[13] National Association for Gifted Children, Position Statement, 2010.

[14] Nemzeti alaptanterv [National Curriculum], Magyar Közlöny 66 (2012) (in Hungarian).

[15] M. Niss, Assessing Mathematical Literacy, Springer, New York, 2014.

[16] M. Niss, Mathematical competencies and the learning of mathematics: the Danish KOM project. Technical report, IMFUFA, Roskilde University, 2002.

[17] OECD, PISA 2015 Assessment and Analytical Framework: Science, Reading, Mathematic and Financial, 2016.

[18] G. Pólya, How to Solve It, A New Aspect of Mathematical Method, Princeton Science Library, Princeton, 2014.

[19] G. Pólya, Mathematical Discovery on Understanding, Learning, and Teaching Problem Solving, Ishi Press, 2009.

[20] P. Rókusfalvy, Tehetséggondozás az iskolában, Elõadások a tehetségrõl [Talent management in school, Lectures about talent], EFO Kiadó és Nyomda Kft., Budapest, 1993 (in Hungarian).

[21] R. R. Skemp, The Psychology of Learning Mathematics, Expanded American Edition (Kindle Edition), Routledge, 2012.

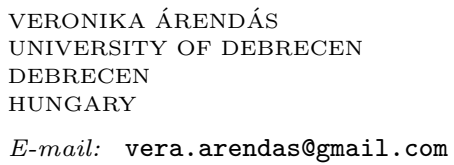

